\title{
150000 Hausbesuche im Museum
}

\section{Eberhard Wolff}

PD Dr. rer. soc., Mitglied der Redaktion Medizingeschichte

Was bleibt vom kompletten Arbeitsleben eines Hausarztes an Greifbarem übrig? Heute wohl kaum mehr als eine volle Festplatte. Der Bieler Arzt Cäsar Adolf Bloesch (1804-1863) notierte über mehr als drei Jahrzehnte 150000 Konsultationen (zumeist Hausbesuche!) von 10 ooo Patientinnen und Patienten in dicke Praxisjournale. Am Ende waren es 55 Bände bzw. drei Laufmeter Aufgeschriebenes. Die im Bieler Stadtarchiv überlieferte, seltene Quelle war das Thema eines medizinhistorischen Forschungsprojekts an der Universität Bern. Jetzt sind die Bände Ausgangspunkt der Ausstellung «Das kranke Biel» im dortigen Neuen Museum (bis 10. Mai).

Eine Vielzahl von Exponaten illustriert Bloeschs Arztpraxis am Ende der "Alten Medizin", die mit ihren Schröpfkuren und traditionellen Arzneipflastern noch der alten Säftelehre verpflichtet war. In seiner Praxis kündigt sich aber schon die neue Medizin an. Er setzte das damals moderne Stethoskop ein und nahm 1848 an der ersten Bieler Operation unter Chloroform-Narkose teil. Vor diesem Hintergrund sind seine unzähligen Aufzeichnungen gründlicher Untersuchungen auch dem Wunsch nach einer systematischen empirischen Fundierung der Medizin geschuldet. Und nicht zuletzt verstand sich Bloesch mit seinen Aufzeichnungen als "Gelehrter», wie sein posthum gemaltes Ölporträt deutlich macht. Auf dem Gemälde verschwinden die klassischen medizinischen Werke im Regal hinter einem Vorhang. Mit der Hand verweist Bloesch auf das für ihn Wichtige, die Erfahrung, die in seinen eigenen Journalen steckt.

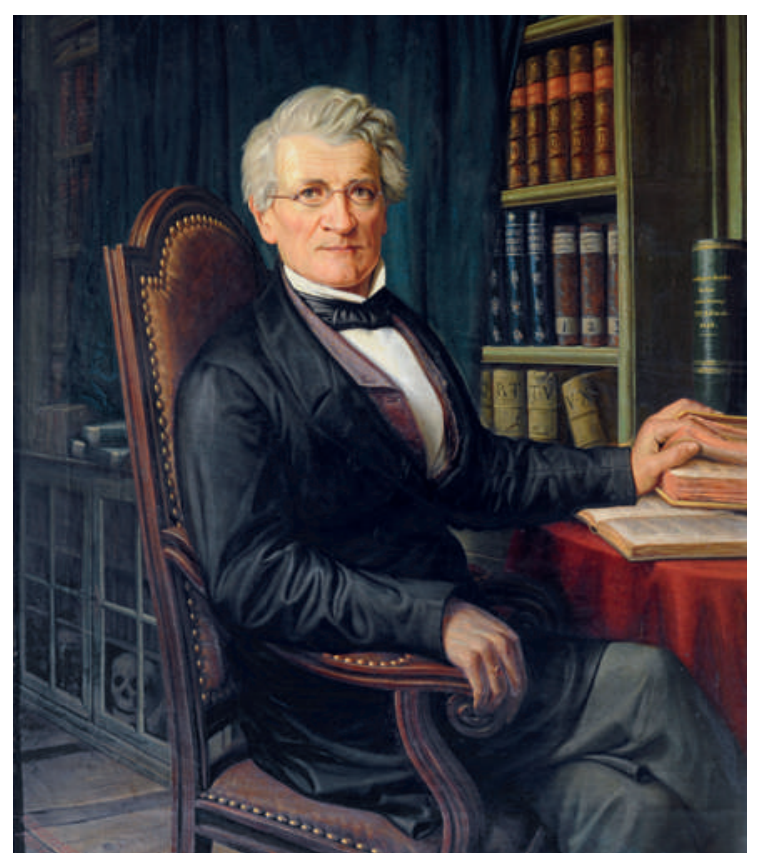

Porträt von Dr. Cäsar Adolf Bloesch, gemalt 1865 von Aurèle Robert (1805-1871) (C Kunstsammlung der Stadt Biel).

Weitere Ausstellungsteile geben einen Einblick die Geschichte Biels und seiner Medizin zu Bloeschs Zeiten. Nicht zuletzt war er Autor einer dreibändigen Geschichte der Stadt.

Ausstellung "Das kranke Biel. Auf Arztvisite um 1850" Bis 10. Mai 2015 im Neuen Museum Biel. Dienstag-Sonntag, 11.00 Uhr bis $17.00 \mathrm{Uhr}$. www.nmbiel.ch

In Zusammenarbeit mit dem Institut für Medizingeschichte der Universität Bern. Der sehr empfehlenswerte Katalog (88 Seiten, Deutsch oder Französisch) ist für 14 Franken im Museum erhältlich.



Die Praxisjournale Bloeschs in Reih und Glied: 150000 Konsultationen von 10000 Patienten. 